this hospital and in other hospitals) performed significantly better $(p<0.05)$ in the practical test than those who had had less than regular training. In addition, the house officers performed significantly better $(p<0.02)$ than the senior house officers.

The Royal College of Physicians has recommended an improvement in training in cardiopulmonary resuscitation and assessment of skills at both undergraduate and postgraduate levels. ' Only a third of this study group had been questioned on cardiopulmonary resuscitation in a formal examination; none had ever been asked to demonstrate their practical skills. The Royal College of General Practitioners is the only royal college that requires examination candidates to be competent in cardiopulmonary resuscitation; perhaps other colleges ought to change their requirements.

Surveys continue to highlight the inadequacies of training in cardiopulmonary resuscitation for junior doctors, ${ }^{6}$ and it is reasonable to assume that these shortcomings will extend throughout the medical hierarchy as time goes by. There is a need for regular training in cardiopulmonary resuscitation and more formal testing of skills both in medical examinations and in the workplace. At present the situation falls far short of the ideal.

Day Surgery Unit,

A P L GOODWIN

Addenbrooke's Hospit

Cambridge CB2 2QQ

1 Morris F, Tordoff SG, Wallis D, Skinner DV. Cardiopul monary resuscitation skills of preregistration house officers: five years on. $B M \mathcal{F}$ 1991;302:626-7. (16 March.)

2 Skinner DV, Camm AJ, Miles S. Cardiopulmonary resuscitation skills of preregistration house officers. BMF 1985;290:1531-2.

3 Safar P, Bircher N. Cardiopulmonary cerebral resuscitation. 3rd ed. London: W B Saunders, 1988

4 Casey WF. Cardiopulmonary resuscitation: a survey of standards among junior hospital doctors. $7 R$ Soc Med 1984;77:921-4.

5 Royal Cunior hospital dociss. $\mathcal{F} R$ Soc Med Cols Cardiopulmonary arrest: training

6 Lum ME, Galletly DC. Resuscitation skills of first year postgraduate doctors. NZ Med f 1989;102:409-11.

\section{Management of childhood diarrhoea by pharmacists and parents}

SIR, - The article by Dr Elizabeth Goodburn and colleagues on managing diarrhoea in children' raises concern about the inconsistent advice that may be given by pharmacists and the inappropriate action that may be taken by parents of young children when dealing with this problem. Pharmacists in Australia have tackled similar difficulties through a structured approach known as pharmacy self care.

This programme is now operating in all Australian states and is supported by both the professional organisation for pharmacists (the Pharmaceutical Society of Australia) and the industrial organisation for pharmacy owners (the Pharmacy Guild of Australia). It has three objectives: to improve community access to quality health information; to increase consumers' health awareness and self reliance in achieving better health and preventing illness; and to equip and encourage pharmacists to give advice and information.

To achieve these aims the programme provides fact cards for the public on 60 health topics; these outline information, warning signs, do's and don'ts for treatment and prevention, and sources of further information. Common topics on which the public seek advice mentioned by Dr Goodburn and colleagues - diarrhoea, coughs and colds, skin problems, and colic-are among those covered. Six times a year health months draw extra attention to particular issues - the need to be wise in the use of medicines being the most recent one.

In addition, self care pharmacists and their staff receive additional training and education by means of audio and visual programmes, visits from an educator, newsletters, and seminars. These resources keep the pharmacists' knowledge up to date and provide the motivation and equipment necessary for them to perform their counselling role effectively.

Although the programme has received some government support, the participating pharmacists substantially finance the management, development, and production of the resources. Promotion of the programme is financially supported in the main by the pharmaceutical industry.

Community pharmacists have an important role in providing accurate health information and advice. In its pharmacy self care programme Australian pharmacy has taken up Professor Michael Rawlins's challenge ${ }^{2}$ in working towards achieving pharmacists' potential as key components of the primary health care network.

Pharmacy Self Care,

PO Box 21,

Curtin,

Australia

Australia

1 Goodburn E, Mattosinho S, Mongi P, Waterston T. Management of childhood diarrhoea by pharmacists and parents: is Britain lagging behind the Third World? BMJ 1991;302:440-3. (23 February.)

2 Rawlins MD. Extending the role of the community pharmacist. BMF 1991;302:427-8. (23 February.)

\section{Community obstetric care}

SIR,-Ms Patricia Street and colleagues audited community obstetric care in West Berkshire in 1987 and 1989, before and after a change in booking policy. ${ }^{1}$ The perinatal mortality rates in 1989 were $8 \cdot 2$ per 1000 in the consultant unit, $5 \cdot 0$ per 1000 in the community unit, and $10 \cdot 2$ per 1000 for complicated obstetric transfers.

My practice has for 20 years operated a minimal selection policy for deliveries in our integrated general practitioner obstetric unit, excluding only women with pre-existing complications and a bad obstetric history. We have monitored the outcome over the past 15 years of our total of 2130 deliveries. We have achieved a perinatal mortality rate of 8.4 per 1000 with a caesarean section rate of $7 \cdot 3 \%$ and a forceps delivery rate of $12 \cdot 3 \%$, the proportion of babies with a birth weight of less than $2000 \mathrm{~g}$ being $4 \cdot 9 \%$.

Although these figures seem to relate quite closely to what might have been achieved in West Berkshire, the timescale over which they were obtained makes them of questionable value as quality indicators of general practitioner obstetric practice as no comparable figures exist. But the dilemma presented to the general practitioner who chooses to undertake the full obstetric care of his patients is whether the advantages of personal continuity of care are balanced by safety for the mother and baby. The annual figures for individual general practitioners are too small to create statistics, and collectively the multiple variables of practices in terms of both demography and obstetric selection policies make general practice statistics meaningless in terms of personal audit.

This is a sensitive aspect of practice open to criticism from many quarters, ${ }^{2}$ and so personal audit is vital to prevent the general practitioner obstetrician being destroyed by anecdotal evidence of cases that have gone wrong. It would seem important, therefore, that each general practitioner as a long term strategy should endeavour to accumulate totals as we have done to try to create some benchmarks of standards. They should then as the opportunity arises make comparison with figures such as those provided by the West Berkshire group.

The general practitioner obstetrician is becoming rare but is not yet extinct, and it is important for the availability of consumer choice that he or she does not become so.

Paxton Green Health Centre,

M P ROSEVEARE

London SE21 8AU

1 Street P, Gannon MJ, Holt EM. Community obstetric care in West Berkshire. BMF 1991;302:698-700. (23 March.)

2 Bryce FC, Clayton JK, Rand RJ, Beck I, Farquharson DIM Jones SE. General practitioner obstetrics in Bradford. $B M \mathcal{J}$ 1990;300:725-7.

\section{Home peak flow meters}

SIR, - In their editorial Drs A S Vathenen and N J Cooke clearly outline the advantages for patients of using peak flow meters in their own homes.' They describe the use of self management plans and say that such plans could be outlined on the asthma cards provided by the National Asthma Campaign (which they refer to as the Asthma Society). Readers may be interested to know that suitable cards are available for both adults and children, and there is also a version for a child to take to school that gives advice to teachers and school assistants on managing that child's asthma. The children's card is also available in Punjabi, Urdu, and Bengali. These cards are available free from the National Asthma Campaign, 300 Upper Street, London N1 2XX, and are supplied with guidelines on their use.

Drs Vathenen and Cooke also refer to the Department of Health's form FP1010 for recording peak flows as being poorly designed. This booklet of charts is now being revised and does have the advantage that it will easily hold together up to one year's recordings rather than the patient having numerous sheets of paper or diary cards.

The National Asthma Campaign strongly supports the wider use of home peak flow meters. The campaign believes that education by verbal, written, and audiovisual means improves a patient's confidence and satisfaction with treatment. For many patients, however, such education will lead to a change in behaviour and a reduction in suffering only when it is coupled with personalised instruction. Such self management plans will nearly always entail objective monitoring with a home peak flow meter.

MARTYN PARTRIDGE

National Asthma Campaign,

London N12XX

1 Vathenen AS, Cooke NJ. Home peak flow meters. BMf 1991;302:738. (30 March.)

\section{Emergency contraception}

SIR,-Dr F C Reader's editorial on emergency contraception' ${ }^{\prime}$ perpetuates the confusion about this subject. Contraception means precisely what it says - that is, prevention of conception. Postcoital contraception is a misnomer as it acts by preventing implantation, as does the intrauterine contraceptive device, which is similarly misnamed.

Can we stop these euphemisms? Interference with potential life which has started at fertilisation should be called by its correct name, abortion. We doctors should be honest with ourselves as well as our patients and be clear in our thinking and teaching. We should also remind ourselves that the Hippocratic Oath states: "I will give no deadly drug to any though it be asked of me, nor will I counsel such, and especially I will not aid a woman to procure abortion."

I do not support applications for abortion, fit intrauterine contraceptive devices, or prescribe postcoital abortive agents as I believe that I should not interfere with what happens after fertilisation. As I cannot force these views on my patients I recommend that they seek another opinion if they so wish. A patient complained to the family health 
services authority because she believed that I should provide the "morning after pill" under my agreement to provide contraceptive services to her. It was only at the informal complaints procedure that the subject was clarified, and no further action was taken. I was advised, however, that I should give patients specific instructions on where to obtain a second opinion and therefore the drugs they demand, the analogy being that I should instruct someone with an injury how to find the accident and emergency department.

PETER J M DAVIS

63 Golf Lane,

Whitnash,

Leamington Spa CV31 2QB

1 Reader FC. Emergency contraception. BMf 1991;302:801. (6 April.)

\section{Diagnosis of unexplained injuries in children}

SIR, - The distinction between non-accidental injury and alternative diagnoses such as osteogenesis imperfecta is both of topical interest and crucially important when assessing children with unexplained injuries. ${ }^{12}$ Dr Magne Nylenna recently referred to the medical dilemmas and uncertainties surrounding the diagnosis of nonaccidental injury. ${ }^{3}$ We report a case that shows how another, much rarer skeletal disorder, Caffey's disease, can easily be misdiagnosed as child abuse.

The fifth child of parents of mixed race living in underprivileged social circumstances was admitted at 2 weeks because of poor feeding and irritability, for which no cause was found. He was readmitted at 6 weeks with swelling and tenderness of the right leg, and radiographic skeletal survey showed symmetric periosteal reactions of the long bones. No mandibular periosteal reaction or wormian bones were seen, and skeletal calcification and serum calcium and copper concentrations and alkaline phosphatase activity were normal. At this stage the diagnosis lay between non-accidental injury and osteogenesis imperfecta. Because an older sibling had been placed on the at risk register when a skeletal survey showed similar periosteal reactions - case conference records then had indicated a family history of violence and criminal behaviour - his name was placed on the child protection register.

Six weeks later he was readmitted because of considerable tenderness and swelling of the right leg. A second skeletal survey showed profuse callus formation and well defined mandibular periosteal reaction, which pointed strongly to a diagnosis of Caffey's disease (infantile cortical hyperostosis).

Initially the combination of unexplained periosteal reactions with poor social circumstances and a history of possible non-accidental injury in an older sibling meant that non-accidental injury was suspected. The inability to make a definitive diagnosis on the first skeletal survey emphasises the necessity to follow up selected cases of suspected non-accidental injury with a delayed skeletal survey. Infantile periosteum becomes visible only four to 10 days after the initial insult, when sufficient calcium to be seen in an $x$ ray film has been laid down; thus an early skeletal survey may not show it.

Although most cases of this increasingly rare idiopathic disorder are sporadic, a few families showing autosomal dominant inheritance have been reported. A genetic aetiology may sometimes be missed as the condition may not have been diagnosed in someone mildly affected in a previous generation, particularly as the outlook for full recovery is good. In familial cases the tibiae, humeri, and ulnae are most often affected, whereas in the sporadic form the mandible, clavicles, and ribs are most often affected. ${ }^{+}$

This case re-emphasises the importance of con- sidering rare alternative diagnoses when assessing a possible case of non-accidental injury. The causes of widespread periosteal reactions in infancy include haemorrhage, inflammation, and infiltration. Thus in addition to non-accidental injury, osteogenesis imperfecta, and Caffey's disease other diagnoses such as leukaemia, scurvy, rickets, viral infections, syphilis, mucolipidosis II, and Menke's disease should also be considered.

A C LAMONT I D YOUNG Leicester Royal Infirmary R S SHANNON

Leicester LE1 5WW

1 Taitz LS. Child abuse and osteogenesis imperfecta. $B M J$ 1987;295: 1082-3

2 Carty H. Brittle or battered? Arch Dis Child 1988;63:350-2.

3 Nylenna $M$. Child abuse or judicial murder in Norway? BMJ 1991;302:371. (16 February.)

4 Maclachlan AK, Gerrard JW, Huston CS, Ives EJ. Familial infantile cortical hyperostosis in a large Canadian family. Can Med Assoc f 1984;130:172-4.

\section{Junior doctors' confidence in their skill in minor surgery}

SIR, - Dr Mike Pringle and colleagues analyse data on the confidence of junior doctors in their skills to carry out certain surgical procedures but do not discuss what such confidence may indicate. Although we are still fairly ignorant about the way professional attitudes and skills develop in doctors in the United Kingdom, there is sufficient evi dence to suggest caution in equating confidence with competence in the early years of training Inappropriate self confidence in their skill has been shown in house officers with regard to resuscitation and has been suggested with regard to cardiotographic monitoring ${ }^{3}$ and urethral catheterisation. Not surprisingly, unsupervised service experience seems to be no substitute for supervised training.

In addition, studies of doctors' professionalisation indicate that pressures on students to perform adequately for their assessors may result in them adopting "cloaks of confidence" with which they may cover up their private uncertainties and inadequacies." My experience of working with clinical students and preregistration house officers suggests that these cloaks of confidence may be used particularly in certain circumstances - for instance, with those who might take legal action or have power to grant or withhold opportunities for career progression. This may be relevant to bodies such as family health services authorities, which must certify doctors who may be admitted on to their lists to perform minor surgery. These junior doctors, however, when not faced with such pressures to be all knowing and competent-and perhaps this was the case in Dr Pringle and colleagues' study-often volunteer that they are distressed by their lack of skills and are only too aware that they may not always do their best for their patients

These questions about the meaning of self reported confidence of junior doctors raise issues beyond those concerning research methods. They should prompt us all to look more critically at the way clinical skills are taught and, in the context of audit by peer group and self learning, the way attitudes to mistakes and criticisms may develop in junior doctors. ${ }^{6}$ In Bristol we are attempting to do this.

\footnotetext{
Department of Epidemiology and

Public Health Medicine,

University of Bristol

Bristol BS8 2PR

1 Pringle $M$, Hasler J, De Marco P. Training for minor surgery in general practice during preregistration posts. BMJ 1991;302 830-2. (6 April.)

2 Marteau T, Wynne W, Evans T. Resuscitation: experience without feedhack increases confidence but not skill. $B M$ 1990:849-50.
}

SUE DOWLING
3 Ennis $M$, Vincent $C$. Obstetric accidents: a review of 64 cases. BMF 1990;300:1365-7.

+ Carter R, Aitcheson M, Mufti GR, Scott R. Catheterisation: your urethra in their hands. BMY 1990;301:905.

5 Haas J, Shaffir W. Ritual evaluation of competence. The hidden curriculum of professionalization in an innovative medical school program. Work and Occupations 1982;9:131-54

6 Light D. Toward a new sociology of medical education. F Health Soc Beh 1989;29:307-21.

\section{Endoscopic and histological findings in subjects with and without dyspepsia}

SIR,-Dr R Johnsen and colleagues found significantly greater prevalences of histological chronic atrophic gastritis and active chronic gastritis in subjects with dyspepsia compared with controls.' Surprisingly, however, histological duodenitis was significantly more common in the control group and endoscopic duodenitis in the subjects with dyspepsia.

Peptic ulcer disease in the study included both active peptic ulceration and deformation of the duodenal bulb. Deformation of the duodenal bulb may cause few symptoms and if unevenly distributed between the groups may have concealed a greater difference in the incidence of active peptic ulceration.

We also have evidence of the lack of correlation between histological abnormalities and gastrointestinal symptoms. We investigated the hypothesis that intolerance to wheat (reproducible gastrointestinal disturbance after eating wheat in a double blind, placebo controlled challenge) is a forme fruste of coeliac disease and associated with histological duodenitis. During 12 months duodenal biopsy specimens were obtained from 12 successive patients with wheat intolerance (eight female, four male; mean age 35 years) and were compared with biopsy specimens from 12 healthy volunteers (six female, six male; mean age 40 years). There was no evidence of villous atrophy in either group. All specimens were normal on visual inspection, but histological duodenitis characterised by an increased inflammatory infiltrate in the lamina propria or an intraepithelial lymphocytosis was found in five of the patients with wheat intolerance and four of the controls.

Our results support the view that histological duodenitis is not associated with gastrointestinal symptoms, and we conclude that wheat intolerance is not associated with abnormal duodenal histological appearances.

S J MIDDLETON J O HUNTER

Gastroenterology Research Unit

Addenbrooke's Hospital

Cambridge CB2 200

I Johnsen R, Bernersen B, Straume B, Forde $O H$, Bostad L Burhol PG. Prevalences of endoscopic and histological findings in subjects with and without dyspepsia. $B M J$ 1991;302:749-52. (30 March.)

\section{Dengue haemorrhagic fever}

SIR, - We would like to add several points to those made by Dr M G Jacobs and colleagues in their report on dengue haemorrhagic fever.

Firstly, our experience confirms the rising numbers of imported cases of dengue. Only three cases were diagnosed in Merseyside between 1986 and 1989 , but in 1990 a dramatic increase was noted, with seven cases being detected. This trend has been seen at other centres nationally, with 106 cases confirmed serologically in the first nine months of 1990 (Public Health Laboratory Service Communicable Disease Surveillance Centre, unpublished data).

Secondly, we would emphasise the debilitating nature of dengue even in the absence of haemor- 